\title{
Oral Health Care Issues in HIV Disease: Developing a Core Curriculum for Primary Care Physicians
}

\author{
Randa Sifri, MD, Victor A. Diaz, Jr, MD, Larry Gordon, DDS, Michael Glick DMD, \\ Howard Anapol, MD, Ronald Goldscbmidt, MD, Deborab Greenspan, BDS, DSc, \\ Richard Sadovsky, MD, MS, Barbara Turner, MD, and Howard K. Rabinowitz, $M D$
}

Background: Given the high occurrence of oral manifestations in patients infected with human immunodeficiency virus (HIV), the relative ease in recognizing these manifestations on physical examination, and their potential impact on the health care and quality of life in these patients, it is critical to provide adequate training for primary care physicians in this area.

Methods: Based on a review of the published literature and the consensus of a national panel of primary care physicians and dentists with clinical and research expertise in this area, a core curriculum was developed for primary care physicians regarding oral health care issues in HIV disease.

Results and Conclusions: We describe the process of developing the core curriculum of knowledge, skills, and attitudes regarding oral health care issues in HIV disease. The final curriculum is in a format that allows for easy accessibility and is organized in a manner that is clinically relevant for primary care physicians. (J Am Board Fam Pract 1998;11:434-44.)

Educating and training primary care physicians in the areas of human immunodeficiency virus (HIV) infection and acquired immunodeficiency syndrome (AIDS) are critically important because the disease is widespread, the geographic distribution of the disease is expanding, and the move toward managed care will likely result in an increasing number of primary care physicians caring for these patients in the future. Oral manifestations are an especially important component of HIV disease, because oral lesions are often the first overt clinical feature of HIV infection. In addi-

Submitted, revised, 29 May 1998.

From the Department of Family Medicine, Center for Medical Education Research and Policy (RS, VD, HKR), the Division of General Dentistry (LG), Department of Medicine, Center for Research in Medical Education and Health Care (BT), Jefferson Medical College of Thomas Jefferson University, Philadelphia; Infectious Disease Program, University of Pennsylvania School of Dental Medicine (MG), Philadelphia; Student Health Services, University of Miami (HA), Miami, Fla; Department of Family Practice, San Francisco General Hospital, University of California (RG), San Francisco; Department of Stomatology, University of California (DG), San Francisco; and Department of Family Practice, SUNY - Health Science Center at Brooklyn (RS), Brooklyn, NY. Address reprint requests to Randa Sifri, MD, Department of Family Medicine, Jefferson Medical College of Thomas Jefferson University, Suite 401 Curtis, 1015 Walnut St, Philadelphia, PA 19107.

This project was supported by the Bureau of Health Professions, under a cooperative agreement for medical education research centers No. 1-U76-MB00002-01, contract No. 103HR960411P, and purchase order No. 97-0300(P)-BHIPR. tion, oral lesions are among the most frequent problems associated with HIV infection, with more than 90 percent of patients having at least one oral manifestation during the course of their disease.

Oral problems almost always produce symptoms, and mouth pain and dysphagia, if untreated, can lead to decreased oral intake and result in weight loss, dehydration, and malnutrition. Appropriate recognition of these lesions is important not only for diagnosis and treatment, but also because many oral manifestations of HIV disease can be markers for deteriorating immune function and can influence recommendations for prophylaxis against specific opportunistic infections. ${ }^{1}$ Additionally, patients with HIV disease might qualify for various clinical trials based entirely on the presence of an oral lesion. ${ }^{2}$

Despite their importance, however, dental and oral problems of HIV infeçtion can be overlooked by physicians, whose education and training in the areas of dental medicine and oral health are often inadequate. ${ }^{3}$ Given that many of these oral lesions are common and can be seen and palpated easily on physical examination, one might expect a general comfort level among physicians in managing oral manifestations. Yet, in one study assessing the ability of primary care physicians to recognize oral findings associated with HIV dis- 
ease, only 22.7 percent were able to diagnose oral hairy leukoplakia. ${ }^{4}$

To address these issues, we undertook a project to develop a core curriculum for primary care physicians regarding the oral manifestations of HIV disease in adults.

\section{Methods}

Under a cooperative agreement and contract with the Bureau of Health Professions (Health Resources and Services Administration), a 5-member project staff including 3 family physicians and 1 general dentist from Jefferson Medical College of Thomas Jefferson University initially sought to describe the core oral health care issues for primary care physicians regarding HIV disease. These issues were then translated into a core curriculum that could be used by primary care residents. Project consultation was provided by a dentist with nationally recognized expertise in HIV disease (MG) and a national advisory committee of 2 family physicians (RG, RS) and 2 general internists (HA, BT) who have experience and expertise in this area, and a dentist nationally known for her HIV research (DG).

Upon completion of a comprehensive review of the literature by the project staff, the consultant and national advisory committee members independently selected those issues that were considered important for primary care physicians regarding the oral manifestations of HIV disease in adults. This information was then reviewed, collated, and prioritized by the project staff and by faculty physicians from the Department of Family Medicine at Jefferson Medical College. Special effort was made to assure that the critical core issues were included and that these issues would be relevant from the primary care perspective. This consensus document was then validated using both the published literature and the database of encounters or questions received from 1991 through 1993 by the National HIV Telephone Consultation Service (Warmline) in San Francisco, a service of the Health Resources and Services Administration AIDS Education and Training Centers. The national advisory committee then continued participation in an iterative process to refine further and finalize these issues by telephone conference call and follow-up written communication.

In a similar fashion, the project staff, using the published literature and consensus of the national advisory committee, developed the core curriculum of knowledge, skills, and attitudes needed by primary care physicians regarding the oral manifestations of HIV disease. The final curricular document was organized in a manner that is clinically relevant for primary care physicians: patients who are seronegative or whose HIV status is unknown, HIV-infected patients with no oral symptoms or lesions, HIV-infected patients who have oral symptoms or oral lesions, and other providerrelated issues. The entire curriculum, including the bibliography, was reviewed and approved by the national advisory committee.

\section{Results}

The completed core curriculum, including photographs of common oral lesions (courtesy of Michael Glick, DMD) and a bibliography, is included in Appendix 1. The main goals of the curriculum are to emphasize the importance of oral health issues and HIV disease and to provide a sound knowledge base for recognizing and managing the common oral problems related to HIV infection. The information was categorized to facilitate easy reference and to reflect the way in which primary care physicians usually approach the care of HIV-infected patients.

To implement this curriculum into a primary care residency program, we recommend integrating it into a broader curriculum that includes management of general oral health problems. Given the 3-year duration of the primary care residency, we recommend that initial exposure to this document occur early during the first year. Because most first-year training is done in the hospital, however, the goals during this year should be limited to learning how to take an oral history and perform a basic oral examination and to understanding the concepts of oral health for HIV-infected and non-HIV-infected patients. In years 2 and 3 of residency training, didactic conferences for HIV-related issues should include specific mention of oral health management. Clinical exposure and teaching should be incorporated during inpatient and outpatient care of HIV-infected patients, and if possible, residents should rotate through the clinical specialties that commonly care for HIV-infected patients who have oral problems, including dentists and infectious disease specialists. 


\section{Discussion}

This curriculum, developed through a multidisciplinary approach combining both primary care physician and expert dental perspectives and provided in a format that allows for easy accessibility, is particularly suited for use by primary care physicians. Although this curriculum was originally designed for implementation at the residency level, the core knowledge content, based on the published literature and on expert consensus, could be used as easily by the practicing primary care physician. Future plans are to distribute this curriculum to all family practice and internal medicine residency programs, as well as to make it available on the World Wide Web.

Generalist physicians are increasingly being asked to expand their knowledge base to incorporate areas frequently within the purview of other specialists, including dentists. Given the widespread oral manifestations of HIV-infected patients, the relative ease in discovering oral lesions on physical examination, and the potential impact on improving the health care and quality of life in these patients, it is critical to provide adequate training for resident and practicing physicians in this area. This document, which can be read easily and quickly in its outline format, will help facilitate this training.

Rosemary Duffy, DDS, MPH, former Deputy Director, Division of Associated Dental Public Health Professions, Health Resources and Services Administration, participated in this project as an initial member of the national advisory committee; and Christina E. Hazelwood coordinated this project.

\section{References}

1. Glick M, Muzyka BC, Lurie D, Salkin LM. Oral manifestations associated with $\mathrm{HIV}$-related disease as markers for immune suppression and AIDS. Oral Surg Oral Med Oral Pathol 1994;77:344-9.

2. Schulten EA, ten Kate RW, van der Waal I. The impact of oral examination on the Centers for Disease Control classification of subjects with human immunodeficiency virus infection. Arch Intern Med 1990;150:1259-61.

3. Curtis JW Jr, Garrison R, Camp M. Dentistry in medical education: Results of a comprehensive survey. J Med Educ 1985;60:16-20.

4. Paauw DS, Wenrich MD, Curtis JR, Carline JD, Ramsey PG. Ability of primary care physicians to recognize physical findings associated with HIV infection. JAMA 1995;274:1380-2.

\section{APPENDIX 1. CoRe Curriculum for Primary Care Physicians Regarding ORal Health CARE ISSUES HUMAN IMMUNODEFICIENCY VIRUS (HIV) DISEASE}

\section{KNOWLEDGE}

Patients Who Are Seronegative or Whose HIV Status Is Unknown

General Guidelines and Recommendations for Oral and Dental Care

1. The US Preventive Services Task Force states that health care providers should counsel patients to visit a dental care provider on a regular basis, floss daily, and brush daily with a fluoride-containing toothpaste

2. There is little scientific evidence regarding the optimal frequency of dental examinations, but many preventive care guidelines do recommend dental examinations every 6 to 12 months

3. Although there are no specific guidelines for physicians regarding when to do an oral history review and physical examination on a noninfected patient, it is clear that all patients should be counseled to avoid the use of tobacco and to use alcohol only in moderation

\section{Oral Symptoms and Oral Lesions and Their Association With HIV Infection}

1. Oral candidiasis can be associated with antibiotic treatment, corticosteroid treatment (inhaled or systemic), diabetes, xerostomia, dentures (or any removable dental appliance), smoking, and defects in cell-mediated immunity

2. No specific literature addresses whether patients with oral candidiasis should routinely be tested for HIV infection. in patients without a clear predisposing condition, however, consideration of immunosuppression should occur

3. Oral hairy leukoplakia and Kaposi sarcoma are rarely seen in immunocompetent patients, and patients who have with these conditions should be encouraged to undergo HIV testing

IIIV-Infected Patients With Neither Oral Symptoms nor Lesions Guidelines and Recommendations for Oral and Dental Care (including who should and when and 
bow to perform an appropriate oral bistory review and physical examination)

1. Based on recommendations from the Agency for Health Care Policy and Research, HIV-infected patients should see a dentist at least every 6 months, or more frequently if severely immunocompromised

2. An oral examination should be done on HIVinfected patients at every physical examination by the medical provider

3. Routine examinations should include careful inspection and palpation of these areas:

a. Lips, especially the corners of the mouth

b. Soft palate and oropharynx

c. Buccal mucosa (inside lips, cheeks), and salivary glands

d. Tongue (including lateral margins, underneath)

e. Teeth (including mobility)

f. Gingiva

4. All mucosal surfaces should be examined using gloves, a tongue blade, gauze squares for extending the tongue, and a light source. A mouth mirror might be necessary for adequate visualization

\section{Counseling and Patient Education}

1. Physicians should recommend daily brushing, flossing, and regular professional care

2. Patients should be instructed to report symptoms of oral pain, dryness, and decreased salivary flow; bleeding; dysphagia; change in taste; and loosening of teeth. Physicians might need to ask the patient about these symptoms

3. Patients should be counseled to avoid the use of chewing and smoking tobacco and to use alcohol in moderation

\section{HIV Prevention, Transmission, and Risk Factors}

1. HIV is found in the saliva, and although oral transmission is thought to be rare, unprotected receptive oral intercourse, even in the absence of mucosal lesions, is a risk for transmission of HIV

2. Casual contact through closed-mouth or social kissing is not a risk for transmission of HIV. Because of the potential for contact with blood during French or open-mouth kissing, the Centers for Disease Control and Prevention (CDC) recommend against engaging in this activity with an infected person
3. It is generally accepted that sharing toothbrushes with patients with HIV should be discouraged

\section{IIIV-Infected Patients With Common Oral Symptoms or Lesions \\ General}

1. Oral care

a. Routine dental visits are recommended every 3 to 6 months if the patient has an oral lesion

b. Use of antimicrobial mouth rinses (eg, chlorhexidine gluconate 0.12 percent [Peridex, PerioGard] 1 tablespoon as a 30-second mouth rinse twice a day) is indicated if the patient has a history of periodontal disease

c. Counseling and patient education as discussed above

2. Pain management

a. Management of pain is essential to avoid malnutrition and decreased medication compliance. Because many symptomatic patients might be unable to tolerate swallowing capsules or tablets, elixirs should be considered for both analgesic and HIV-related medications

b. Treatment options include analgesic-anesthetic mouth rinses and topical medications (eg, viscous lidocaine), systemic nonnarcotic medications (eg, nonsteroidal anti-inflammatory drugs, acetaminophen), and narcotic agents for acute pain episodes, or psychotropic medications (eg, tricyclic antidepressants, selective serotonin reuptake inhibitors) for chronic pain syndromes

\section{Nutrition}

a. Patients at risk might need to use antiemetic or antidiarrheal agents to help them avoid precipitation or exacerbation of malnutrition

b. Complete and supplemental nutritional products (eg, Ensure) are available for patients at risk for malnutrition

c. Physicians should consider referring patients for nutritional counseling in certain cases

d. Physicians should be aware of possible $B_{12}$ and folate deficiency and be able to recognize these clinical conditions

4. Patient education and patient support network a. Physicians should instruct the patient's part- 


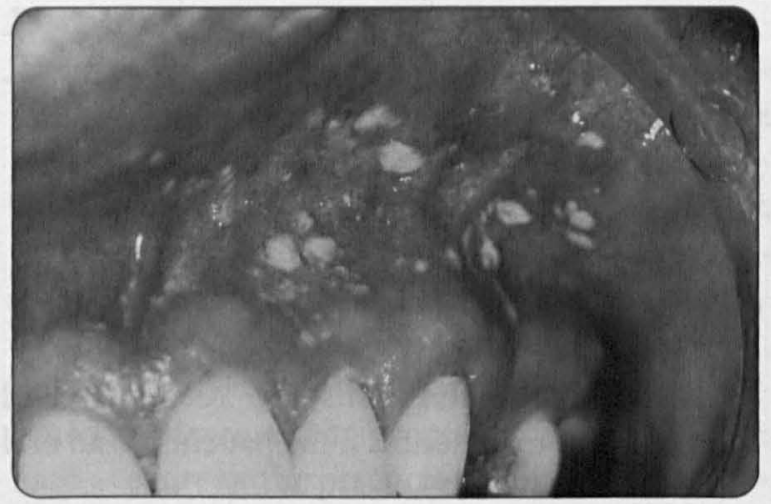

Figure 1. Pseudomembranous candidiasis.

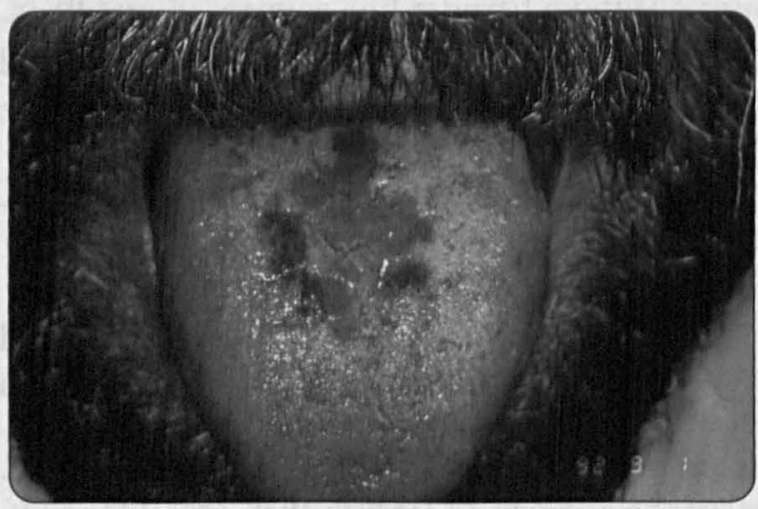

Figure 3. Erythematous candidiasis.

ners, relatives, and friends on how to perform an appropriate oral screening examination

b. Written materials, on-line sites, and other national and local resources are available for patients and their partners, relatives, and friends

5. HIV-related medication side effects

a. Common medications used to treat HIV disease have side effects that can include increased caries; xerostomia (see Other Oral Conditions, below); discoloration of skin, mucosa, and saliva; oral and esophageal ulcers (see Recurrent Aphthous Ulcers, below); sore throat and mouth; and perioral paresthesias

b. Anecdotal evidence suggests that protease inhibitors may lead to an increased incidence of caries

\section{Oral Candidiasis}

1. Epidemiology: Oral candidiasis is a very common fungal infection that is seen in more than 95 percent of $\mathrm{HIV}$-infected patients during the course of their illness

2. Appearance (including various presentations),

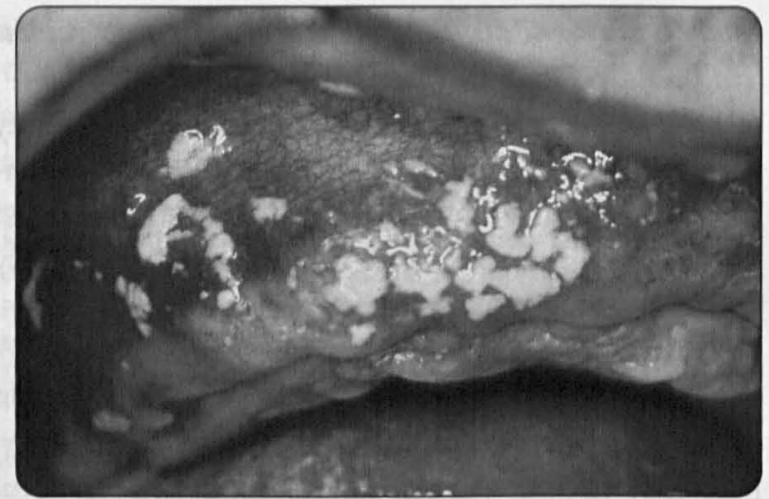

Figure 2. Pseudomembranous candidiasis.

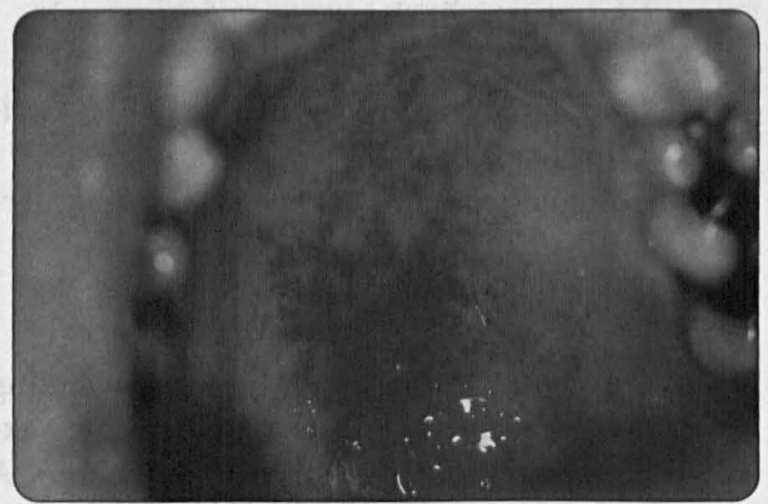

Figure 4. Erythematous candidiasis.

recognition, and diagnosis

a. Oral candidiasis can manifest in 4 different ways:

i. Pseudomembranous candidiasis or thrush (Figures 1 and 2): removable whitish plaques that can occur on any oral mucosal surface. Pr zsumptive diagnosis can be made based on clinical appearance and response to antifungal medications

ii. Erythematous candidiasis (Figures 3 and 4): smooth, red, atrophic patches that can occur on the hard or soft palate, buccal mucosa, or the tongue. Differential diagnosis includes geographic tongue and nutritional deficiencies. Diagnosis can be based on clinical appearance, nutritional history, duration and stability of the lesion, and treatment response

iii. Hyperplastic candidiasis (Figures 5 and 6): nonremovable whitish plaques, sometimes associated with a burning sensation, that can be found on any mucosal surface. The differential diagnosis can include oral hairy leukoplakia (see Oral Hairy Leukoplakia, below)

iv. Angular cheilitis: fissures radiating from 


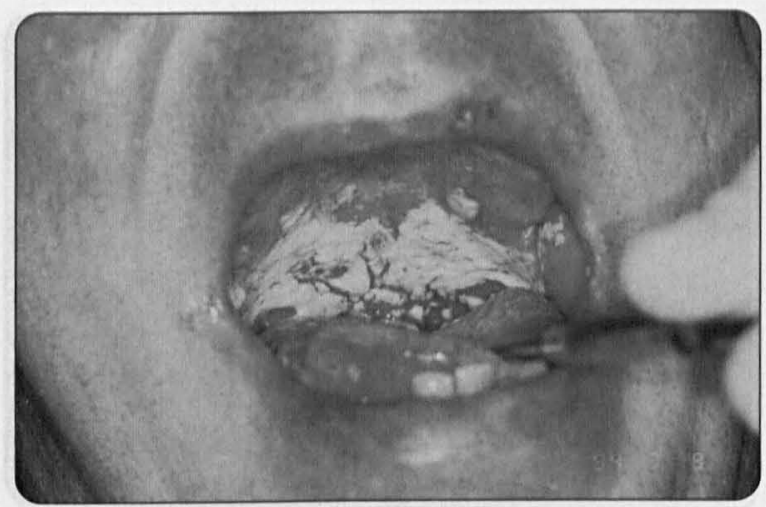

Figure 5. Hyperplastic candidiasis.

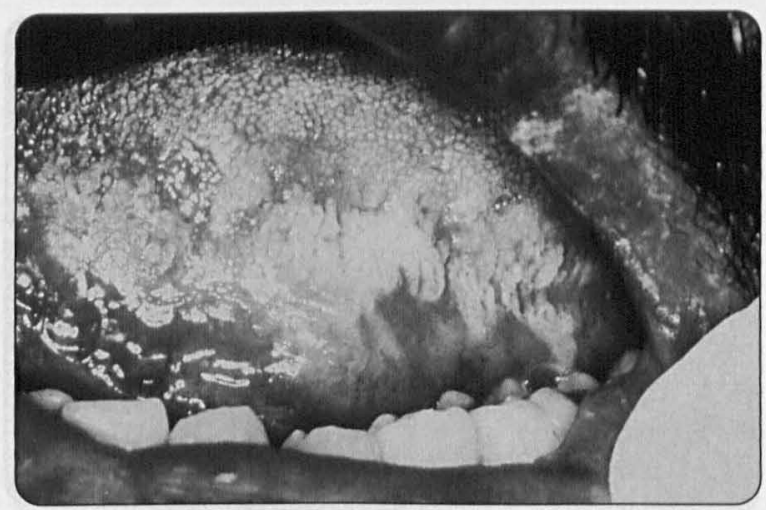

Figure 7. Oral hairy leukoplakia.

the corners of the mouth that are sometimes covered with a removable white membrane. These fissures are sometimes found in conjunction with xerostomia

b. Because candidal organisms are ubiquitous in healthy oral mucosa, potassium hydroxide testing of these lesions is rarely helpful

3. Treatment and resistance

a. Management can depend on the patient's CD4+ (T-helper) lymphocyte count and the resistance of the organisms to medication

b. Empiric therapy may be initiated based on a presumptive diagnosis of oral candidiasis

c. First-line oral topical therapy includes nystatin pastilles and vaginal clotrimazole troches; oral troches and suspensions are more cariogenic than vaginal troches

d. Topical therapy is most useful when CD4+ cell counts are higher than $150 / \mu \mathrm{L}$

e. At lower CD4+ cell counts, systemic therapy might be necessary. Oral fluconazole is often the first drug of choice

f. In cases of drug resistance, other imidazoles, eg, itraconazole, or intravenous amphotericin, might be required

g. Treatment should be continued until 2 to 3

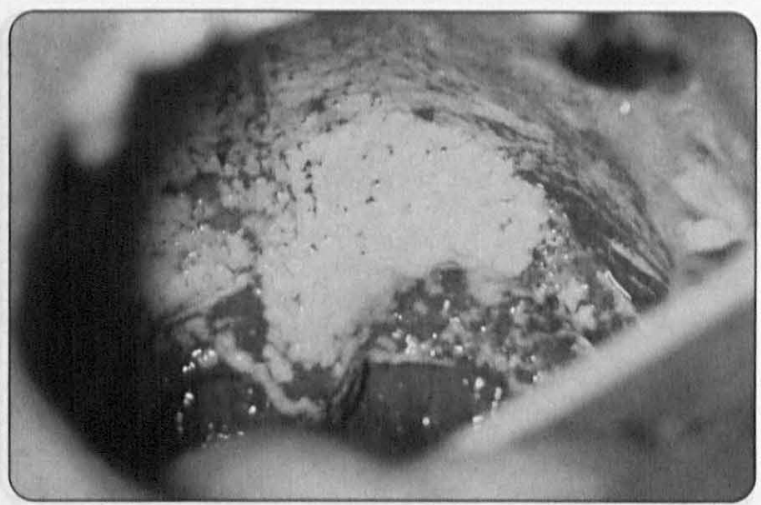

Figure 6. Hyperplastic candidiasis.

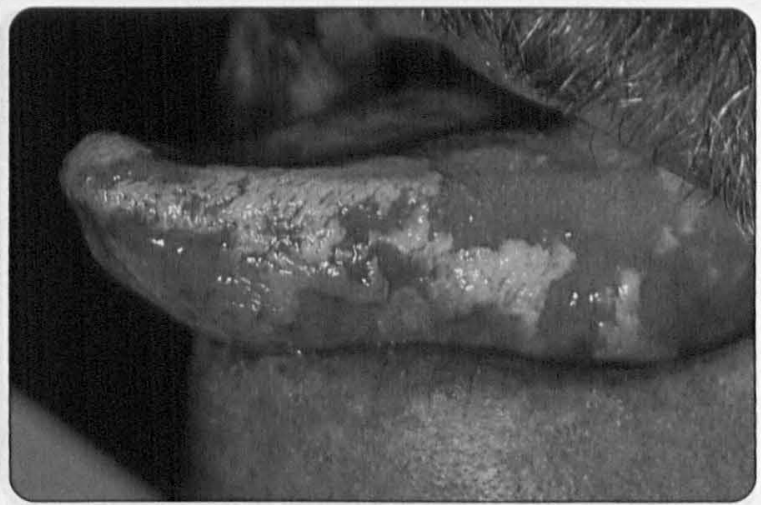

Figure 8. Oral hairy leukoplakia.

days after the disappearance of clinical signs

h. There are no CDC guidelines for prophylaxis against candidal infections based on CD4+ cell counts; however, prophylaxis with antifungal medications might be recommended in cases of high recurrence

4. Clinical and prognostic importance

a. Oral candidiasis is commonly seen in both $\mathrm{HIV}$-positive and uninfected patients and is therefore not considered a diagnostic marker for AIDS (see Oral Symptoms and Oral Lesions, and Their Association with HIV Infection above). Nevertheless, oral candidiasis in HIV-positive patients has been established as a precursor to AIDS within 1 to 2 years of its appearance

b. The frequency and type of candidiasis are usually indicative of disease progression. Hyperplastic candidiasis is usually associated with severe immunosuppression and almost always requires treatment with intravenous therapy

c. The CDC recommends Pneumocystis carinii pneumonia (PCP) prophylaxis in all HIVpositive patients with a history of oral candidiasis, regardless of CD4+ cell count. It is 


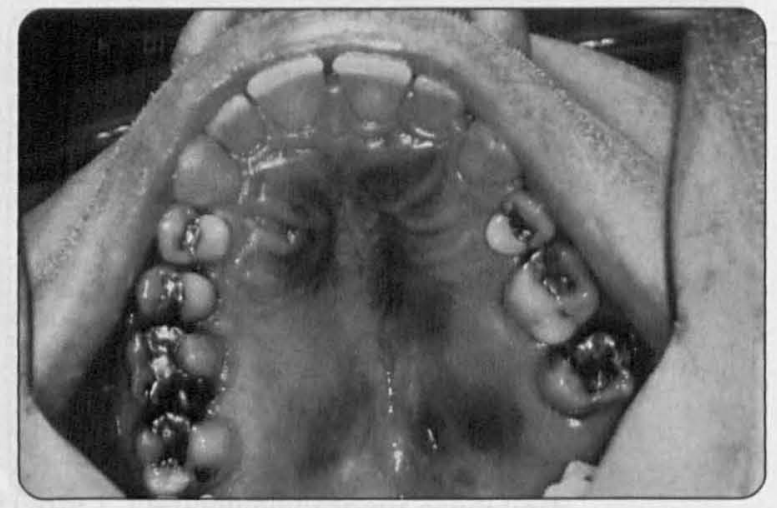

Figure 9. Kaposi sarcoma.

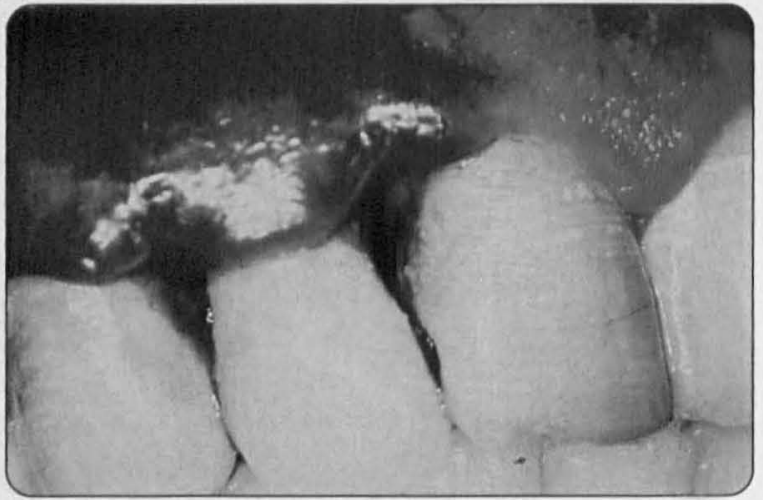

Figure 11. Necrotizing ulcerative periodontitis.

unclear how often this recommendation is followed

5. Esophageal candidiasis

a. Patients with oral candidiasis who complain of dysphagia, dysgeusia (abnormal taste), or retrosternal discomfort are at risk for esophageal candidiasis and should be examined by endoscopy

\section{Oral Hairy Leukoplakia}

1. Epidemiology

a. Oral hairy leukoplakia is found most commonly in male homosexual AIDS patients but is not considered diagnostic for AIDS

b. The lesions are associated with the EpsteinBarr virus.

2. Appearance, recognition, and diagnosis (Figures 7 and 8)

a. Lesions are whitish, nonremovable, vertically corrugated hyperkeratotic patches typically found on the lateral margin of the tongue

b. A presumptive diagnosis can be based on clinical appearance and location. A definitive diagnosis requires finding the EpsteinBarr virus on a biopsy of the lesion, but it is

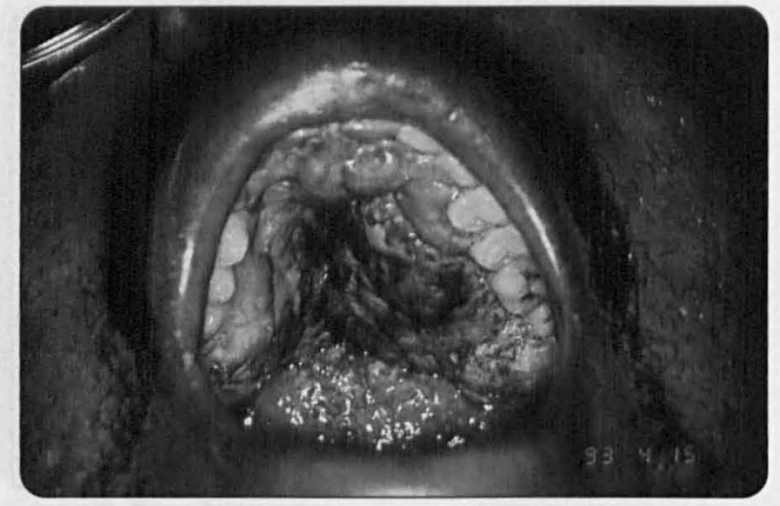

Figure 10. Kaposi sarcoma.

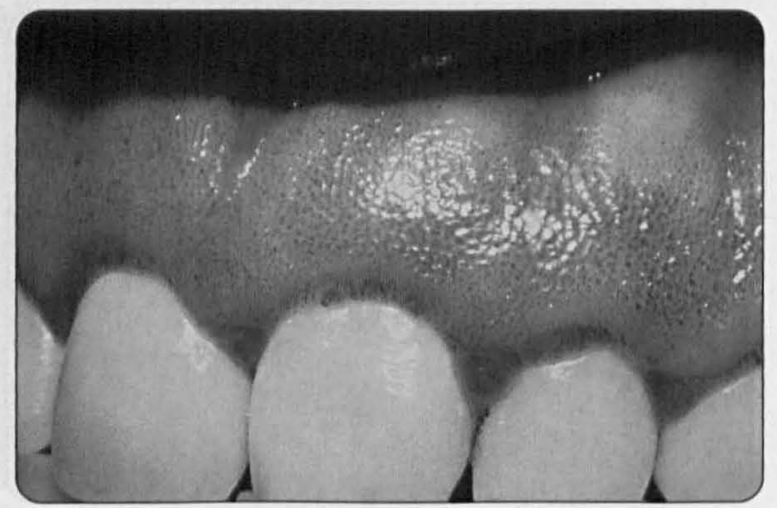

Figure 12. Linear gingival erythema.

not essential

3. Management and treatment

a. Treatment is palliative only and is not necessary if the lesion is asymptomatic

b. Lesions can respond to acyclovir, ganciclovir, tricyclic antidepressants, podophyllin, and retinoids, but usually recur after treatment is completed

4. Clinical and prognostic importance; transmission

a. Oral hairy leukoplakia can be a marker for disease progression and immunosuppression

b. There is no known shedding of the EpsteinBarr virus; transmissibility through intimate contact is unknown

\section{Kaposi Sarcoma}

1. Epidemiology

a. Kaposi sarcoma is a lymphoproliferative neoplasm found most commonly in male homosexual AIDS patients

2. Appearance, recognition, and diagnosis (Figures 9 and 10)

a. Lesions can appear as macules, patches, nodules, or ulcerations that are bluish, brownish, or reddish 


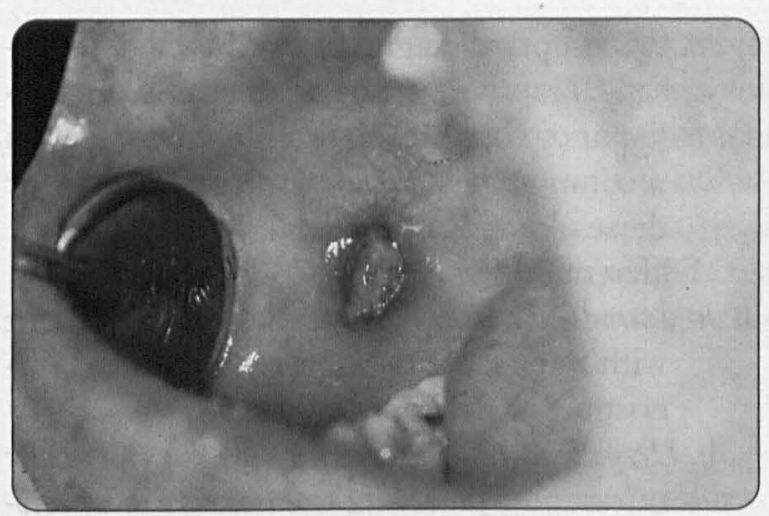

Figure 13. Minor apthous ulcer.

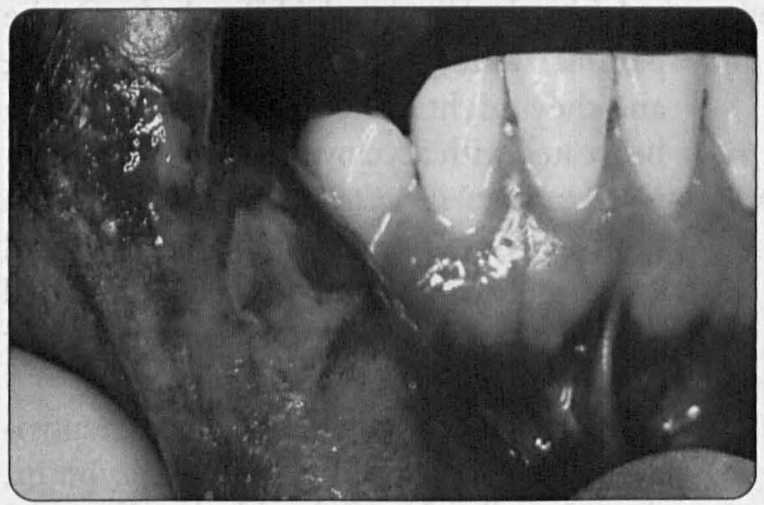

Figure 15. Herpes simplex ulcer.

b. Kaposi sarcoma can be found anywhere in the gastrointestinal tract and is commonly seen on the hard or soft palate and gingiva

c. Differential diagnosis can include nonHodgkin lymphoma (ulcerative), bacillary angiomatosis, and physiologic pigmentation (macular)

d. Definitive diagnosis of Kaposi sarcoma as an AIDS-defining lesion requires biopsy

3. Management and referral

a. Management requires referral to an oral oncologist or an experienced oral health care provider

b. Treatments include radiation, intralesional chemotherapy, and less often, surgery

4. Clinical and prognostic importance

a. Kaposi sarcoma in an HIV-infected patient is diagnostic for AIDS and is indicative of severe immunosuppression

b. Kaposi sarcoma can occur intraorally, either alone or in association with skin, visceral, and lymph node lesions

\section{Periodontal Disease}

1. Epidemiology

a. Periodontal disease is the most common

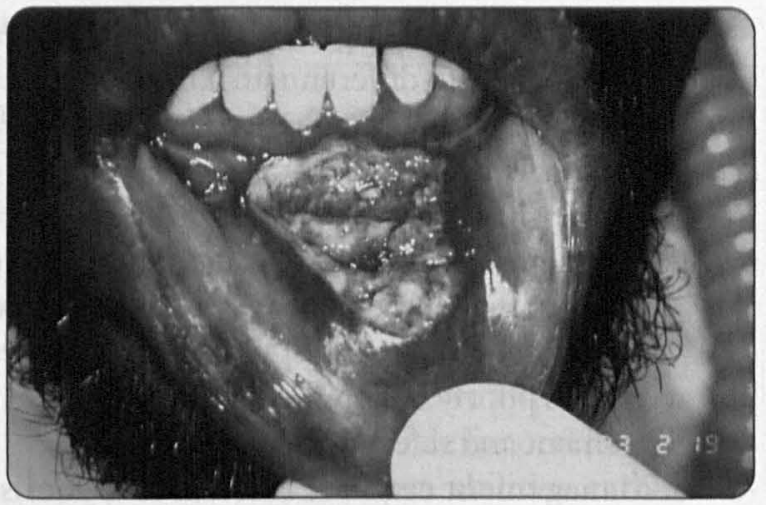

Figure 14. Major apthous ulcer.

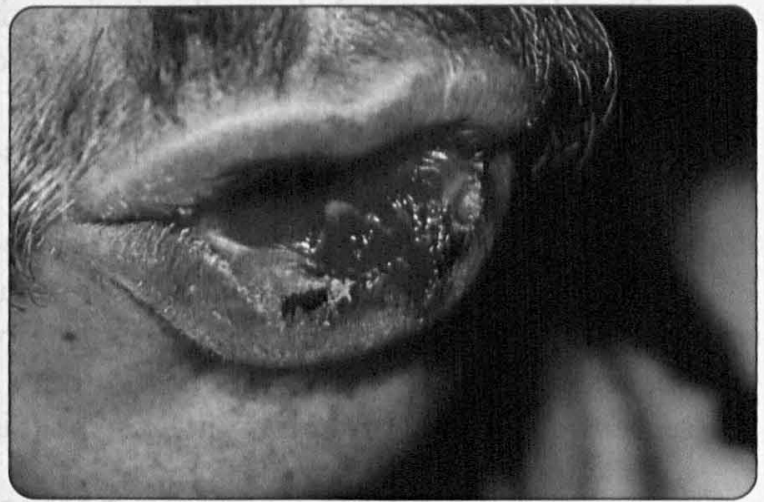

Figure 16. Herpes simples ulcer.

oral bacterial infection among HIV-infected patients, and a very destructive type is seen more commonly in homosexual and bisexual men and smokers

b. There are no clearly known specific causative agents; the periodontal flora of HIV-infected patients is no different from that of non-HIV-infected patients. Poor diet, poor oral hygiene, and xerostomia can increase the incidence of plaque, which can lead to periodontitis

c. Conventional or non-HIV-linked periodontal disease is as common in HIV-infected patients as in the general population

2. Symptoms, appearance, and recognition

a. The most common manifestations of HIVassociated periodontal disease include necrotizing ulcerative periodontitis and linear gingival erythema

b. Necrotizing ulcerative periodontitis (Figure 11) is rapidly progressive, causes extensive destruction of bone and periodontal tissue, is extremely painful, and is accompanied by spontaneous bleeding and halitosis. It is distinguished from conventional periodontitis by its accelerated rate of progression and its 
deep-seated nongingival pain. It can also require biopsy to differentiate it from other lesions, eg, non-Hodgkin lymphoma and cytomegalovirus infection

c. Linear gingival erythema (Figure 12) occurs as a 2- to 3-mm erythematous band on the gingiva accompanied by mild pain and spontaneous bleeding. This condition responds poorly to conventional therapy

3. Treatment and referral

a. Management requires referral to a dentist for frequent visits

b. Dental treatment includes antibiotics, mouth rinses, irrigation with povidone iodine, and mechanical cleaning

4. Clinical and prognostic importance; transmission

a. Necrotizing ulcerative periodontitis is associated with severe immune deterioration. Linear gingival erythema might be a precursor to necrotizing ulcerative periodontitis

b. Transmissibility through intimate contact is unknown

5. Prevention and oral care

a. Patients should rinse with chlorhexidine, as well as brush their teeth and gums and floss regularly

\section{Recurrent Aphthous Ulcers}

1. Epidemiology

a. There is no known etiologic agent for recurrent aphthous ulcers, but stress, acidic foods, and tissue-barrier breakdown have been reported to precipitate their occurrence

b. Ulcers can be found in both HIV-infected and uninfected patients

c. Ulcers can be more severe and prolonged in HIV-infected patients but occur no more commonly than in the general population

2. Appearance, recognition, and diagnosis

a. Ulcers are variable in size and can be shallow or deep

b. Minor ulcers (Figure 13) are 2 to $5 \mathrm{~mm}$ in diameter, covered by a pseudomembrane, and surrounded by an erythematous halo

c. Major ulcers (Figure 14) are greater than 10 $\mathrm{mm}$ in diameter, painful, persist for months, and can cause odynophagia and impairment of speech and swallowing

d. Lesions usually involve the nonkeratinized (movable) oral mucosa e. Presumptive diagnosis can be made clinically; biopsy rules out other causes (eg, malignancy, opportunistic infections) and is recommended for major ulcers and for those ulcers that do not improve

3. Differential diagnosis

a. Iatrogenic ulcers can result from treatment with zalcitabine, foscarnet, interferon, vincristine, or radiation

b. Herpetic ulcers (Figures 15 and 16) can occur intraorally, involving the keratinized (nonmovable) oral mucosa, and periorally, involving the lips and skin; they can be painful, solitary or multiple, and vesicular; and they might coalesce. These ulcers can be treated with acyclovir

c. Cytomegalovirus ulcers are painful, with punched-out, nonindurated borders and are usually associated with disseminated disease. They can be treated with acyclovir or ganciclovir

d. Otber ulcers can be caused by severe neutropenia, squamous cell carcinoma, syphilis, deep fungal infections, and mycobacterial infections

4. Therapeutic management

a. Palliative therapy includes analgesic-anesthetic mouth rinses and topical ointments

b. Corticosteroids can be effective as a topical medication, a mouth rinse, or an oral medication. Prolonged use of oral corticosteroids can exacerbate immunosuppression

c. Alternative treatment options include thalidomide given orally, or Mile's mixture (tetracycline, nystatin, hydrocortisone) given as a mouth rinse

d. Lesions should be reevaluated after 1 to 2 months of treatment

5. Clinical and prognostic importance

a. Major ulcers are associated with severe immunosuppression

\section{Other Oral Conditions}

1. Parotid gland enlargement is found more commonly in HIV-infected children, is usually nontender, and can be either unilateral or bilateral. It can occur during the course of HIV disease or as a medication side effect. Xerostomia can occur secondarily and should be treated. Surgery is indicated only for cosmetic reasons 
2. Xerostomia, or reduced salivary flow, promotes dental caries and periodontitis. Patients will complain of dry mouth and require frequent dental visits. Treatment is symptomatic and includes artificial saliva, chewing or sucking sugarless candy, cholinergics, etc. Xerostomia can be caused by medications (eg, zidovudine, didanosine, foscarnet)

\section{Provider Issues}

\section{Universal Precautions and Occupational Exposure}

1. Universal precautions are adequate protection for the medical and dental provider, unless the patient has also been diagnosed with active tuberculosis

\section{Medical Issues Related to HIV-Infected Patients Who Have Oral Manifestations}

1. Indications for antibiotic prophylaxis for dental procedures

a. Guidelines set by the American Heart Association for subacute bacterial endocarditis prophylaxis are the same for both HIV-infected and uninfected patients

b. If the absolute neutrophil count is less than $500 / \mu \mathrm{L}$ and the patient is not receiving bactericidal antibiotics, the patient should receive prophylactic antibiotics. A low $\mathrm{CD} 4+$ cell count as such does not definitively suggest the need for antibiotics

2. Bleeding precautions

a. In patients with a history of impaired hemostasis, the platelet count, prothrombin time (PT), partial thromboplastin time (PTT), and complete blood cell count should be determined before planning extensive surgical intervention

b. Most routine dental procedures can be done if the platelet count is greater than $60,000 /$ $\mu \mathrm{L}$ and if the PT and PTT are less than two times the normal range

3. There are no major healing differences between HIV-infected patients compared with nonHIV-infected patients, even if the HIV-infected patient is severely immunosuppressed

4. Most dental needs of the HIV-infected patient can be provided by general dentists, and they, as with all other health care providers, are obligated by the Americans with Disabilities Act to provide care for HIV-infected patients

\section{ATTITUDES}

Physician Attitudes Should Reflect the Following:

1. Compassion and objectivity when dealing with issues related to HIV disease

2. Awareness of the value of a comprehensive oral examination for early detection and care of patients with $\mathrm{HIV}$ disease

3. Awareness that primary care physicians, as well as dentists, are responsible for oral health care

4. Awareness of one's own abilities and limitations and the need for further consultation when appropriate

5. Acceptance of responsibility to act as the patient's advocate and to help with access within the health care system

6. Recognition of the importance of educating and involving $H \Gamma$-infected patients, their partners, and caregivers in their oral care

7. Understanding of the impact that oral lesions can have on a patient's overall health and wellbeing

\section{SKILLS}

Physician Skills Should Enable the Physician to Do the Following:

1. Take an appropriate oral history and perform a comprehensive oral examination

2. Perform appropriate screening and preventive oral health care

3. Recognize and manage common oral health problems seen in HIV-infected patients

4. Counsel and educate HIV-infected patients, their partners, and their caregivers about oral care

5. Know when and to whom to refer patients for further case evaluation and management

6. Access medical resources, including the Internet and MEDLINE, for additional information

\section{Bibliography}

American Academy of Family Physicians. Recommended core educational guidelines for family practice residents: HIV infection/AIDS. AAFP reprint no 273. Kansas City, Mo: American Academy of Family Physicians, Feb, 1992

Brahim JS, Roberts MW. Oral manifestations of human immunodeficiency virus infection. Ear Nose Throat J 1990;69:464. 467-9,472-4.

Centers for Disease Control and Prevention. Transmission 
of HIV possibly associated with exposure of mucous membrane to contaminated blood. MMWR 1997;46: 620-3.

Cooney TG. Clinical management of the complications of HIV infection. J Gen Intern Med 1991;6(1 Suppl): S12-8.

Dental management of the HIV-infected patient. J Am Dent Assoc 1995;126(Suppl): 1-40.

Duffy RE, Adelson R, Niessen LC, Wescott WB, Watkins $\mathrm{K}$, Rhyne RR. VA oral HIV surveillance program: understanding the disease. J Am Dent Assoc 1992;123: 57-62.

Evaluation and management of early HIV infection. Rockville Md: US Department of Health and Human Services, Agency for Health Care Policy and Research, 1994. [AHCPR publication no. 94-0572.]

Facts about the human immunodeficiency virus and its transmission. In Centers for Disease Control and Prevention. HIV/AIDS prevention. Rockville, Md: CDC, December, 1995.

Glick M, editor. Clinician's guide to treatment of HIV-infected patients. New York: American Academy of Oral Medicine, 1996.

Glick M. Dental management of patients with HIV. Carol Stream, Ill: Quintessence, 1994.

Glick M, Muzyka BC, Lurie D, Salkin LM. Oral manifestations associated with HIV-related disease as markers for immune suppression and AIDS. Oral Surg Oral Med Oral Pathol 1994;77:344-9.

Goldschmidt RH, Dong BJ. Treatment of AIDS and HIVrelated conditions-1997. J Am Board Fam Pract 1997; 10:144-67.

Greenspan D, Greenspan JS. HIV-related oral disease. Lancet 1996;348:729-33.

Greenspan D, Greenspan JS. The mouth in human immunodeficiency virus infection. Semin Dermatol 1994; 13:144-50.

Greenspan D, Greenspan JS. Oral manifestations of HIV disease. In: Freidman-Kien AE, Bralow L, Fletcher J, editors. Color atlas of AIDS, 2nd ed. Philadelphia: WB Saunders, 1996.

Greenspan D, Greenspan JS. Oral manifestations of human immunodeficiency virus infection. Dent Clin North Am 1993;37:21-31.

Greenspan D, Greenspan JS, Schiødt M, Pindborg JJ. AIDS and the mouth. Copenhagen: Munksgaard, 1990.

Greenspan JS, Barr CE, Sciubba JJ, Winkler JR. Oral manifestations of HIV infection. Definitions, diagnostic criteria, and principles of therapy. The USA Oral AIDS Collaborative Group. Oral Surg Oral Med Oral Pathol 1992;73: 142-4.

Hayward RS, Steinberg EP, Ford DE, Roizen MF, Roach KW. Preventive care guidelines: 1991. American Col- lege of Physicians. Canadian Task Force on the Periodic Health Examination. United States Preventive Services Task Force. Ann Intern Med 1991;114:758-83.

Jacobson JM, Greenspan JS, Spritzler J, Ketter N, Fahey $\mathrm{JL}$, Jackson JB, et al. Thalidomide for the treatment of oral aphthous ulcers in patients with human immunodeficiency virus infection. National Institute of Allergy and Infectious Diseases AIDS Clinical Trials Group. N Engl J Med 1997;336:1487-93.

Kline MW. Oral manifestations of pediatric human immunodeficiency virus infection: a review of the literature. Pediatrics 1996;97:380-8.

Lamster IB, Begg MD, Mitchell-Lewis D, Fine JB, Grbic JT, Todak GG, et al. Oral manifestations of HIV infection in homosexual men and intravenous drug users. Study design and relationship of epidemiologic, clinical, and immunologic parameters to oral lesions. Oral Surg Oral Med Oral Pathol 1994;78:163-74.

Paauw DS, Wenrich MD, Curtis JR, Carline JD, Ramsey PG. Ability of primary care physicians to recognize physical findings associated with HIV infection. JAMA 1995;274:1380-2.

Palacio H, Milton JF, Canchola AF, Greenspan K. Effect of cigarette smoking on HIV-related oral lesions. J Acquir Immune Defic Syndr Hum Retrovirol 1997;14:338-42.

Schacker T, Collier AC, Hughes J, Shea T, Corey L. Clinical and epidemiologic features of primary HIV infection. Ann Intern Med 1996;125:257-64.

Schulten EA, ten Kate RW, van der Waal I. The impact of oral examination on the Centers for Disease Control classification of subjects with human immunodeficiency virus infection. Arch Intern Med 1990;150:1259-61.

Scully C, Laskaris G, Pindborg J, Porter SR, Reichart P. Oral manifestations of HIV infection and their management. I. More common lesions. Oral Surg Oral Med Oral Pathol 1991;71:158-66.

Thompson SH, Charles GA, Craig DB. Correlation of oral disease with the Walter Reed staging scheme for HIV1-seropositive patients. Oral Surg Oral Med Oral Pathol 1992;73:289-92.

USPHS/IDSA Guidelines for the prevention of opportunistic infections in persons infected with human immunodeficiency virus: A summary. Atlanta, Ga: US Dept of Health and Human Services, Public Health Service, Centers for Disease Control and Prevention, 1995. [Morbidity and mortality weekly report: recommendations and reports, vol 44, no RR-8.]

US Preventive Services Task Force Staff. Guide to clinical preventive services: report of the United States Preventive Services Task Force. 2nd ed. Baltimore: Williams \& Wilkins, 1996.

Weinert M, Grimes RM, Lynch DP. Oral manifestations of HIV infection. Ann Intern Med. 1996;125:485-96. 